\title{
La Colmena
}

Pliego de Poesía

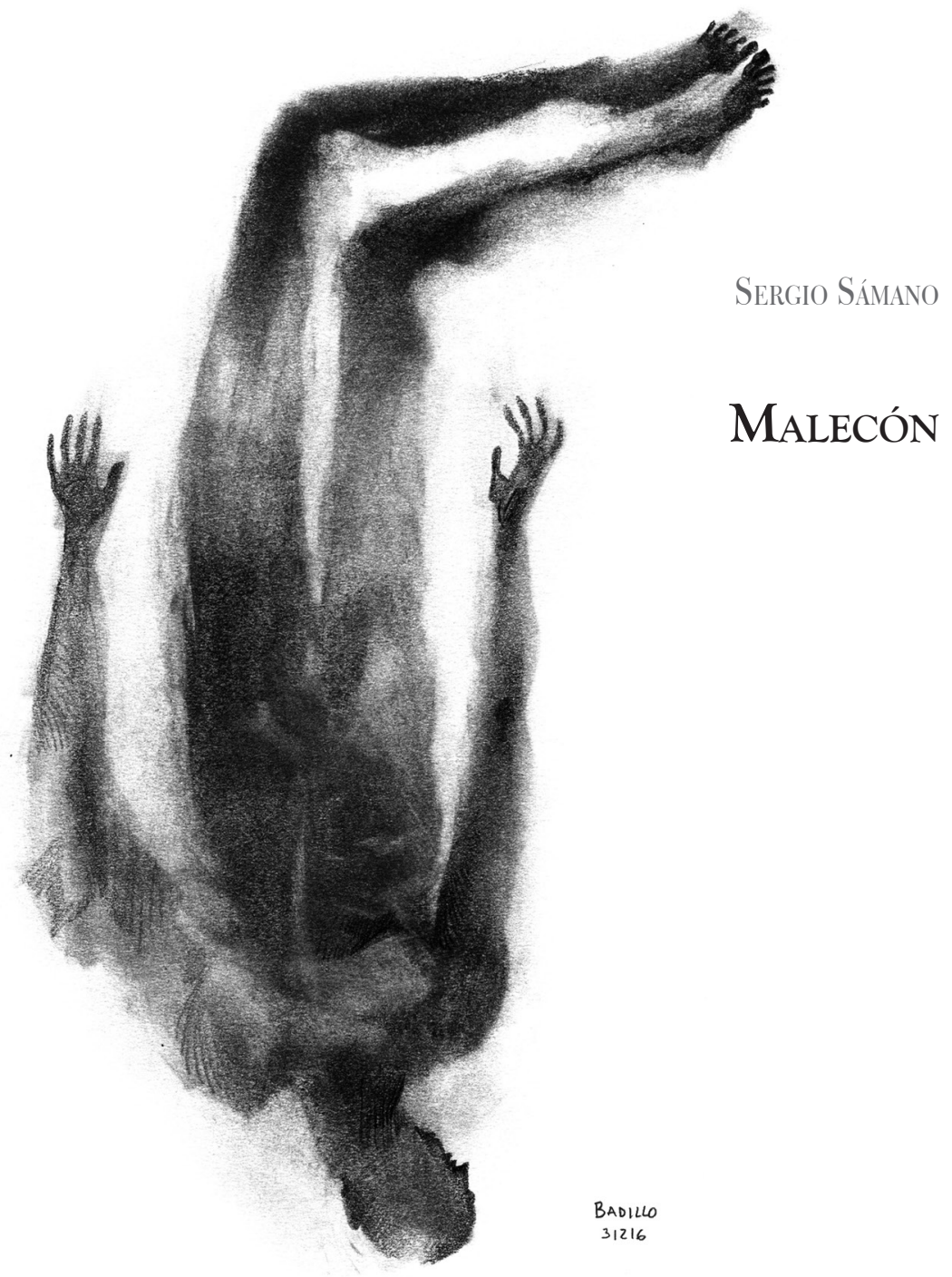

REVISTA DE LA UNIVERSIDAD AUTÓNOMA DEL ESTADO DE MÉXICO Número 106 Abril-Junio de 2020 
Portada: Hombre en descevso, de la SeRie ObRa Pictórica (2016)

Lápiz: Carlos Alberto Badillo-Cruz

MaQuetación: Francisca Miranda-Mendoza.

Pliego de Poesía, núm. 106, abril-junio de 2020, es una separata de La Colmena, que es publicada, distribuida y editada trimestralmente por la Universidad Autónoma del Estado de México a través de su Secretaría de Difusión Cultural. Sor Juana Inés de la Cruz No. 300, col. 5 de Mayo, Toluca, Estado de México, C.P. 50090, Tels.: (722) 2773835 y 277 3836, http://acolmena.uaemex.mx. Editor responsable: Jorge E. Robles Alvarez. Reserva de Derechos al Uso Exclusivo No. 04-2000-012811362600-102, ISSN: 1405-6313, ambos otorgados por el Instituto Nacional del Derecho de Autor, Licitud de Título No. 8133 y Licitud de Contenido No. 5763, otorgados por la Comisión Calificadora de Publicaciones y Revistas Ilustradas de la Secretaría de Gobernación. Impresa por Editorial Cigome, S. A. de C. V., Oriente 241 A N.28 bis, col. Agrícola Oriental, Del. Iztacalco, Ciudad de México, tel. 57003534 . Este número se terminó de imprimir en junio de 2020 con un tiraje de 500 ejemplares. Las opiniones expresadas por los autores no necesariamente reflejan la postura del editor de la publicación. Esta obra está sujeta a la licencia Reconocimiento-NoComercial-SinObraDerivada 4.0 Internacional de Creative Commons. Para ver una copia de esta licencia, visite https://creativecommons.org/licenses/by-nc-nd/4.0/ 


\section{I}

Estoy ciego de tanto mar,

de tanta luz.

Rostros se difuminan en la bruma de las olas

somos uno

en la danza del mar.

Malecón

en la danza del agua

prorrumpen chorros vivientes

calientes

sangre-salada-silenciosa

canta el aire

y el fuego arrecia a mediodía.

Por la tarde vuelve la ceguera

con este sol que me derrite,

sol que seduce,

sol que toma mis manos y dirige mis pasos. 
Malecón

dame tus dedos,

ivamos a volar!

Mira los peces incendiarse entre las flores de primavera

toma el venado de la tierra colorada

y ocúltalo en esos barcos, en la caldera extraña.

Malecón

déjame ir al faro

a buscar mi norte

lo anclé en la isla de piedra

desde entonces ató su cintura a mi ladera.

Me seduce el Trópico de Cáncer,

culpo un embrujo,

arte de hechicería;

pero es mi alma cincelada en sal,

de tanto andar marejadas,

la que se descubre inerme

entre la espuma moliente. 
Malecón

horizonte-espejo infinito de las olas rotas,

de la lluvia que no cesa,

de la ciudad que no va más;

horizonte-espejo cuasiforme de la noche y del día.

\section{VI}

Malecón

mis labios extrañan un cuerpo,

una nota,

un aire a serranía.

Sus manos recorren tus huesos,

la busco y no hallo su vientre ajeno.

Escucho la oleada silenciosa,

respiremos juntos la brisa

sin la ninfa durmiente. 


\title{
VII
}

Malecón

\author{
zig-zag de la vida-muerte \\ del mar en calma, \\ del mar en furia, \\ de la bendita suerte marina.
}

\section{VIII}

Malecón

Baila entre sueños de los mortales,

vamos al mar,

vamos a amar,

deja que el mundo se pierda en la temporal eclosión. 


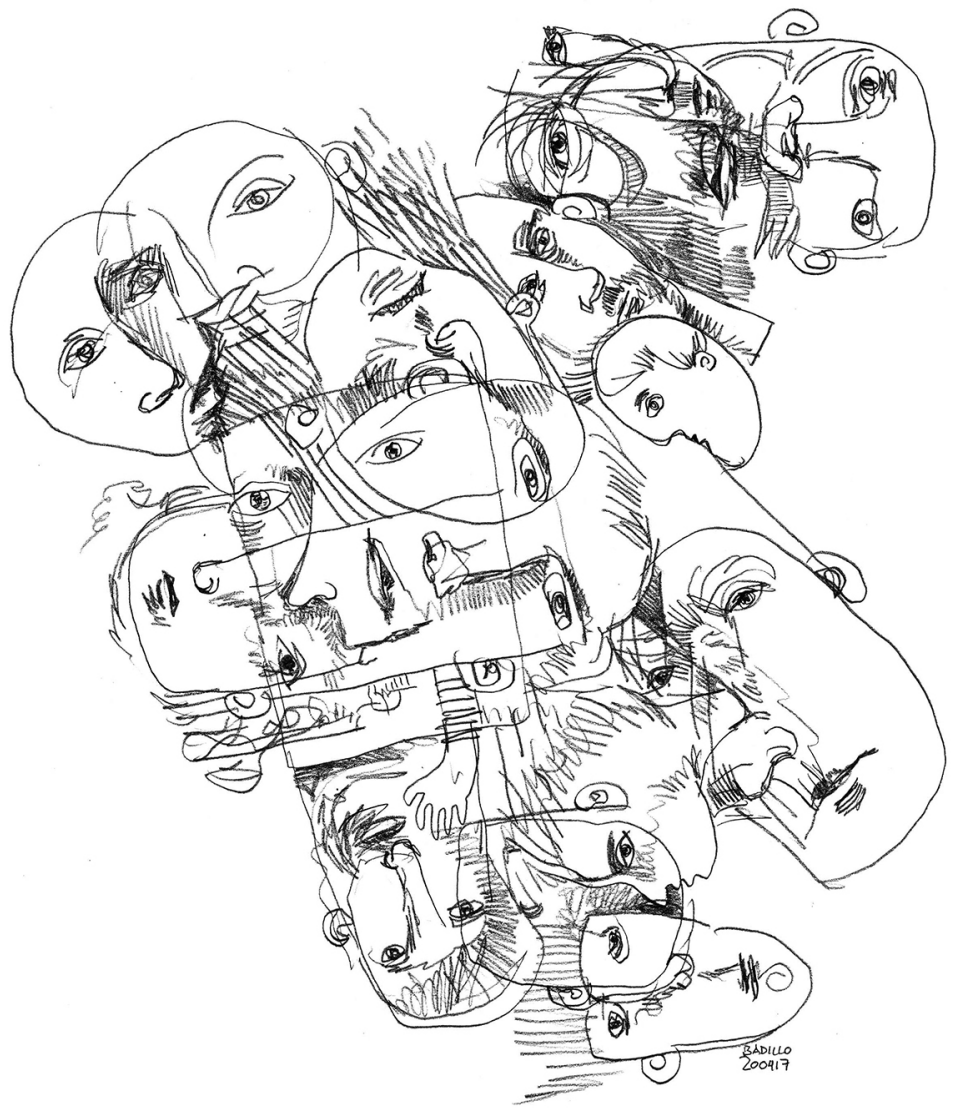

Caras cruzadas, de la serie Dibujo simple (2017). Lápiz: Carlos Alberto Badillo-Cruz. Prohibida su reproducción en obras derivadas. 
Malecón

levanta la furia del tiempo

va arremolinada en el aire

allá en la espuma,

allá en la arena,

en las rocas,

en los choques de olas,

en las gotas que caen y se vuelven mar,

en los suspiros que se vuelven el último,

en lo que somos y nos volvemos nada,

nos volvemos todo,

nos volvemos polvo.

\section{$\mathrm{X}$}

Malecón

mis pasos no van más,

la edad rompió las ligas que me sostienen.

Te sigo amando

aunque mis pies no dan más pasos en tu piel.

Mis cenizas vendrán a parar aquí,

no llores por los que ya no podemos amar,

la vida es nuestro pequeño tiempo. 
Malecón

sigue danzando

ola-silente

ola-danzante

ola-caliente

ola-amante

amante-ola

caliente-ola

danzante-ola

silente-ola

danzando sigue

Malecón

XII

Malecón

no bastan mis palabras.

Se acaba mi tiempo en la dulce mar-tierra,

no hay más suspiros

con lo que sobra

y un poco de arte macabra:

te miro

y mis deseos son humo.

Si me dejas andar, otra vez,

caminar tu largo cuerpo

aunque sean cenizas mi piel. 


\section{XIII}

Malecón

vine a cantarte

como las hordas de bardos de todos lados

mi voz es la de cualquier otro

un canto oxidado

un viejo molino a la sombra del sol

y heme aquí, como tu hijo, que sólo desea una cruz de palabras Malecón

\section{XIV}

Malecón

de noche dejan su rastro en esa ola-terrestre

la luz de las estrellas,

la luna,

los buques y barcos,

las lámparas de la civilización que te estrecha, en un choque desaparecen y vuelven a nacer toda luz nocturna

armoniosa,

danzante,

candente. 


\section{XV}

Malecón

vientos alisios perfuman tu vientre,

los fuertes redoblan las plazas,

y las tierras inertes en espera de esa lluvia que no cesa de no llegar.

La mar hace lo suyo

ser mar y devorar lo que esté a su paso,

un día - dicen - todo será mar

después, el sol nos incendiará.

\section{XVI}

Malecón

hay muchas historias en las calles vecinas:

una cuenta la de los seres que fueron arrastrados por la codicia,

otra de aquellos que retumban sus vientres;

más allá la de un café; donde se toma el tiempo a sorbos.

Hay tantas historias que las palabras dejan de tener sentido.

Hace tanto tiempo que dejamos escrito el tiempo,

que el tiempo nos borró de la tierra.

Somos un recuerdo viviente de lo que nunca ha sido

de lo que es y no existe,

de lo que no ha existido o dejó de existir.

Una existencia en palabras huecas,

huecas de tanto no caber que se hicieron grandes para ajustarse a los espacios,

huecas de haber sido desgarradas por los seres que tienen historias inexistentes. 


\section{XVII}

Malecón

hijo del calor,

parido por el tiempo

Eres una palabra, y en otras lenguas, eres una cosa.

Somos una cosa,

somos animales irreducibles,

reconstruidos,

que al final se destruyen.

\section{XVIII}

Malecón

ven a bailar de nuevo,

ven a vivir otra vez,

ven con la música entrelazada en las palabras orbes

y en la invasión de cada año

te damos vida en este día.

No es verdad,

sin ti no tendríamos a quién cantar,

a quién bailar,

a quién ser de nuevo otro ser,

... tú nos das vida. 


\section{XIX}

Malecón

tiene tanta tristeza el abandono de tus cantos

como las hojas caídas en la primavera.

La canción que no se canta más

se olvida,

se llena de telarañas.

XX

Malecón

después de muchos días en la mar

las palabras rasgan el cielo,

dibujan gaviotas,

anuncian buen puerto

comida

agua

y cobijo. 


\section{XXI}

\section{Malecón}

he de partir hoy,

seguir el ritual,

la rutina,

seguir las olas-terrestres que acompañan a la vida-muerte.

Hace tiempo que no navego el mar que resguardas.

Tomar una barca para partir.

¿quién festeja una partida?

No ir por tesoros o a conquistar nuevas tierras.

Tampoco se llevan valiosas mercancías,

sólo la barca para andar el tiempo-marino,

que nos lleva a otro puerto.

Tomo la edad que ha deshojado mi cuerpo;

un poco más viejo

quizá más sabio o más necio,

pero más cercano a la ceguera del tiempo:

así le llaman a aquella parca que cerrará estos ojos.

Tomo la barca de Ulises para ir a mi Ítaca,

la que nos dice Kavafis y nos enseñó Homero:

llegar a buen puerto; aunque no lleves riquezas ni conquistas cantadas,

llevas una vida que vale cada palabra.

Espero llegar más longevo,

con aquellos que — sin riqueza y sin gloria-,

me siguen amando en sus ojos;

quizá llegue a un puerto solitario

o uno bullicioso,

sólo espero ser amado

en el último día de mi vida en la mar. 


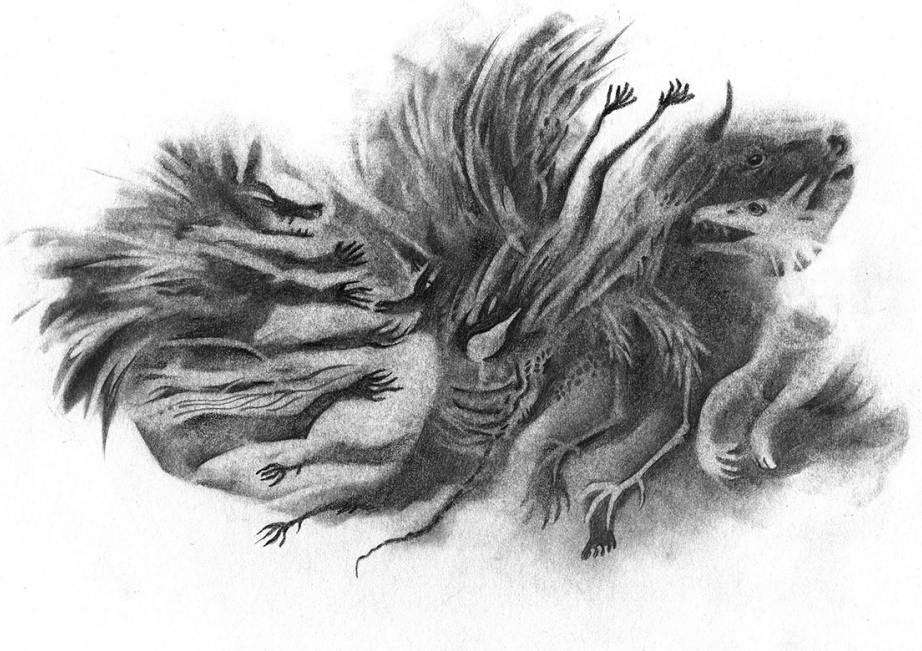

Lobos y aves, de la serie Dibujo de arte (2016). Lápiz: Carlos Alberto Badillo-Cruz.

Prohibida su reproducción en obras derivadas.

Sergio Sámano (1979, Toluca). Estudió Física e idiomas (sueco, rumano, inglés, árabe) en la Universidad Nacional Autónoma de México (UNAM), México. En 1996 comenzó a participar en distintos talleres de creación poética, incluido el de lectura de Margarita Monroy Herrera y el de Blanca Aurora Mondragón. En 2016 se integró a la Colectiva Voluta y fundó la estación Voluta radio, donde realizó actividades de promoción cultural, divulgación de la ciencia, tianguis culturales, conciertos, proyecciones, charlas, entrevistas. Asiduo asistente y organizador de algunos de los cafés literarios tunAstral de 2017 a 2019. Actualmente, toma cursos en Nox Escuela creativa de escritura con León Placencia Nol y Carla Faesler.

Recibido: 26 de septiembre de 2019

Aprobado: 5 de junio de 2020 
